\title{
LA SUJECIÓN EN EL PANORAMA EDUCATIVO \\ DESPUÉS DEL “FIN DE LA HISTORIA"
}

\section{The subjection in the educational panorama after of "end of history"}

\author{
LUIS RODOLFO LÓPEZ MOROCHO \\ Ministerio de Educación / Quito-Ecuador \\ luis2_1_21@hotmail.com \\ Código Orcid: http://orcid.org/0000-0003-1598-4236
}

\begin{abstract}
Resumen
El presente trabajo parte del análisis sobre el fin de la historia, que tiene su origen en la interpretación que realiza Kojève de la filosofía de la historia de Hegel, que será continuada y reformulada por Fukuyama. Se examinarán los principales aportes de estos tres pensadores en la construcción de esta categoría con su respectiva repercusión en el mundo actual, develando una relación invisibilizada entre los planteamientos de este último y la protofilosofía de la historia agustiniana. Una vez elaborado el marco de referencia del fin de la historia se presentarán las críticas realizadas por Butler y Cadahia sobre el papel que juegan como mecanismos de dominación sobre toda una maquinaria antropológica denominada posthistoria. Posteriormente, se reflexionará en torno al marco de la sujeción anterior, enfatizando en sus implicaciones dentro del campo educativo. Para ello se dialogará con dos autores, en principio, contrapuestos, Foucault y Freire, en disputa por el presente de la educación. La metodología genealógica permitirá visibilizar el comienzo de la escuela tal y como se la conoce en la actualidad atendiendo a sus condiciones de posibilidad concretas dentro de un entramado de poderes determinados. En este sentido, la sujeción jugará un papel fundamental en la conformación de un sujeto educativo contemporáneo que se verá desbordado y será precisamente en esta crisis donde existirá una posibilidad de elección: esperanza o sujeción.
\end{abstract}

Palabras clave

Historia, filosofía, escuela, educación, esperanza.

Forma sugerida de citar: López M., Luis R. (2018). La sujeción en el panorama educativo después del "fin de la historia”. Sophia, colección de Filosofía de la Educación, 25(2), pp. 185-208.

* Master (c) de Investigación Filosofía y Pensamiento. Licenciado en Filosofía y Pedagogía. Docente de Especialización en Educación con Personas Jóvenes y Adultas de CREFAL Paraguay. Analista de Currículo en Ministerio de Educación Ecuador. 


\begin{abstract}
The present research will analyze "the end of history", which had origined in the interpretation realized by Kojève about the philosophy of the history proposed by Hegel and finally completed and reformulated by Fukuyama. Then I will analyze main contributions of these three thinkers in the construction of this category with their respective repercussions in the real world, and I will establish a relationship between the approaches of Fukuyama and the protophilosophy of Augustinian history. After I elaborate the framework about end of history, I will present the criticisms realized by Butler and Cadahia about its roles like mechanisms of domination over all anthropological machinery and posthistory. Finally, I will do some reflexions about framework of the subjection in order to apply this on the education. For this reason, I will establish a dialogue between two authors, Foucault and Freire, and I will use opposing arguments about currently education. The genealogical methodological will be able to view the beginning of school as we know at present, and considering its conditions of possibility inside of a determinate power structure. In this way, the subjection will be fundamental in the current educational subject construction that will be seeing desbodated, and this crisis will obligate to choose hope or subjection.
\end{abstract}

Keywords

186 History, philosophy, school, education, hope.

\title{
Introducción
}

El presente trabajo está estructurado en dos partes, la primera tiene como objetivo general identificar la relación existente entre la filosofía de la historia de Hegel y el concepto fin de la historia planteado, en un primer momento por Kojève (2013) para ser continuado, difundido y consolidado, más recientemente por Fukuyama (1992), con su respectivo impacto en el mundo contemporáneo en diferentes ámbitos.

En primer lugar, es necesario caracterizar brevemente la filosofía de la historia en Hegel, en este sentido, dada la extensión del trabajo, solo se sintetizarán sus aportes más significativos que vienen dados, a juicio del autor, por la libertad y la relación entre historia e historiador traducida en sujeto-objeto, intentando seguir la metodología dialéctica que él utiliza, desembocando en una breve reflexión sobre sus implicaciones en lo que posteriormente Kojève (2013) llamará el fin de la historia.

Posteriormente se analizará la interpretación que realiza Kojève (1992), evidenciando la originalidad de sus pensamientos bajo su intento de interpretar a Hegel, donde destacan dos aspectos fundamentales, el primero es el fin de la historia y el segundo es el papel de la libertad en este desenlace. Para él, en la dialéctica del amo y del esclavo, hay una supuesta liberación a través del trabajo, sin embargo, se verá con la ayuda de Cadahia (2012) y Butler (2001), que lo que surge es una forma de autoesclavización, una forma de conciencia servil respaldada por toda una maquinaria antropológica. Además, se apreciará como la interpretación 
de Kojève (2013) fue un claro precedente de la lectura liberal que realizará posteriormente Fukuyama (1992) sobre el fin de la historia. Fruto de esta relación se intentará mapear una relación inconfesada del estadounidense con la protofilosofía de la historia planteada por San Agustín de Hipona.

Enseguida se analizará el discurso elaborado por Fukuyama (1992) donde se evidenciará cómo pone la interpretación de Kojève (2013) al servicio de la democracia liberal, aludiendo a la autoridad de Hegel, y realizando planteamientos sobre el fin de la historia, relacionados con la geopolítica de su tiempo, que han marcado de una u otra manera el pensamiento contemporáneo. En este sentido, se analizarán sus planteamientos liberales y los motivos de su supuesto éxito, al punto de ser considerado como lugar de llegada de la historia universal y marquen el inicio de lo que se conocerá como posthistoria.

Se pondrá de relieve cómo el fin de la historia y la consecuente construcción de la posthistoria se utilizaron en el ámbito del biopoder para la dominación, ejecutada a través de la democracia liberal de mercado, donde se produce una gestión de la vida política mediada a través de mecanismos y estrategias de dominación que evidencian Cadahia (2012) y Buttler (2001) mediante una metodología genealógica.

La segunda parte, siguiendo la misma metodología se reflexionará en torno a la labor educativa actual sobre la base de los planteamientos anteriores realizados acerca de la sujeción. Se pondrán en diálogo a dos autores a priori confrontados, Foucault (2003) y Freire (1993). Una vez acercados al horizonte de reflexión de ambos es necesario contextualizar la educación en la época contemporánea para poder analizar su rol en la sociedad.

Ambos tienen visiones totalmente contrapuestas frente a la realidad educativa. Vale mencionar que Foucault, pese a reflexionar y nombrar en varios de sus libros a la escuela, nunca realizó un trabajo sistemático sobre ella, es por ello necesario decir que se enfatizará sobre todo en la metodología usada por el autor para el análisis de la educación, la genealogía. Freire por el contrario sí realiza una reflexión sobre la educación siendo, de hecho, la columna vertebral de su obra.

\section{Filosofía de la historia en Hegel}

El autor coincide con Salvador Rus (2005) al pensar que la historia es fundamental en la construcción del pensamiento hegeliano, concretamente de su sistema filosófico. En primer lugar, es necesario considerar que Hegel concibe la historia como realización de la libertad, y su propuesta es 
una filosofía pensante de la historia, considerando que esta no es trascedente sino inmanente. Además, es importante no ignorar que la filosofía hegeliana es un sistema complejo que abarca multitud de dimensiones, por lo que en el presente trabajo solo se abordará algunas implicaciones acerca su filosofía de la historia, sin pretender abarcar todo el complejo sistema hegeliano.

Uno de los textos que pueden ser fundamentales a la hora de acercarse a la filosofía de la historia en Hegel, a juicio de Rus (2005), es Lecciones sobre la filosofía de la historia donde el autor "reflexionó profundamente sobre la realidad histórica en la que vivió y trató de comprender" (p. 28). En este sentido, es fundamental considerar que el autor trató de explicar la historia desde sus orígenes hasta el momento mismo donde estaba, en otras palabras "comprender todo lo que aparecía ante su mi188 rada e integrarlo dentro de un sistema filosófico propio" (p. 28). Es fundamental considerar el contexto del autor para poder entender su obra, y en Hegel es particularmente importante al existir una clara intención de actuar en su tiempo, en este sentido Napoleón y su actuación histórica son fundamentales dentro de su pensamiento histórico.

Es necesario para comprender el pensamiento hegeliano utilizar su método por antonomasia, la dialéctica en sentido especulativo. Por ello, es clave aclarar que se entiende a la dialéctica no como sistema totalizador que no da lugar a las diferencias, sino como Aufhebung, que Reale \& Antiseri (1988) exponen como "el momento especulativo es un superar en el sentido de que al mismo tiempo es un suprimir y conservar" (p. 113). En otras palabras, los términos nacen a la vez, A y B, hay algo de A en B y algo de $B$ en A. Aparece una grieta donde se produce una cancelación y una conservación, una contaminación de ambos.

Como ya se ha mencionado, para Hegel la evolución de la historia se ve como un desarrollo de la libertad, de este modo la historia universal, citando a Rus (2005), es un "conjunto de fases o épocas históricas que se van sucediendo temporal y dialécticamente en un progresivo avance hasta el establecimiento del estado, única forma en la que los individuos viven plenamente en libertad" (p. 33). De este modo, Hegel realiza una especie de recorrido histórico que va desde Oriente hasta su mundo germánico, pasando por la Grecia clásica y el mundo Romano. En el último estadio las naciones "han llegado a la conciencia de que el hombre es libre como hombre y que todos han nacido para ser libres" (p. 35). Es importante mencionar que en este punto no se habla de fin de la historia, pero muchas lecturas posteriores han visto como necesidad lógica colocar aquí esta noción como plantean Reale \& Antiseri (1988): 
¿Acaso la historia está destinada a detenerse en la fase cristiano-germánica?, ¿deja acaso de avanzar, en determinado momento, la dialéctica histórica? Esto es lo que habría que deducir de las palabras de Hegel, al revés de lo que exigirían necesariamente los principios de la dialéctica misma. Se trata de una seria aporía que también repercutirá sobre la concepción de la historia de Marx (p. 150).

La filosofía de la historia hegeliana parte de los hechos históricos, que son una parte fundamental, su materia prima, pero va más allá de ellos. Su visión es racional, pues la razón será la que nos permitirá ver cómo ha evolucionado el mundo. Esto se puede comprender de mejor manera. Como plantea Rus (2005) al conocer los "tres tipos diferentes para escribir y hacer historia" (p. 38), pues el autor realizará una visión retrospectiva del modo en que se ha hecho historia antes que él y querrá superar todas estas posiciones usando una metodología dialéctica. Para Hegel existen tres tipos posibles de historia que a saber son original, reflexiva y pensante. Todas ellas pueden entenderse a partir de la relación entre sujeto-objeto que marcará también el papel de la libertad en cada una de ellas.

La primera, la historia original, está caracterizada por ser la más primitiva, tiene un punto de partida necesario, pero no suficiente. En este tipo de historia los historiadores son meros testigos de lo que sucede, describen en primera persona aquello que han vivido y experimentado, se puede ver una clara similitud con los cronistas. En este sentido, no son capaces de tomar distancia de lo vivido, ir más allá, pues forman parte de aquello que acontece. Su papel es insuficiente, al no existir un trabajo mediado por la razón en la historia, "el espíritu en el cual el historiador escribe la historia original es el mismo con el que él se enfrenta a las acciones" (p. 39). Aquí hay una subordinación de los hechos al pensamiento, la libertad no es posible pues no hay mediación de la razón, sujeto y objeto se identifican. El historiador es uno mismo con la historia, por ende, el desarrollo de la libertad no puede darse.

La historia reflexiva empieza a trabajar desde el entendimiento, por ello se logra ir más allá de lo que está presente en el propio historiador toda vez que existe un tipo de reflexión. Sin embargo, aquí el sujeto mira al objeto como ya dado, en otras palabras, aparece una especie de dualismo entre objeto y sujeto, son independientes uno del otro. En este sentido, el historiador toma el papel de espectador, "es una historia de la historia" (p. 40). Dentro de este tipo de historia Hegel realiza una serie de subcategorías, en las cuales puede empezar a visualizarse un sentido pedagógico y moral de la historia, pues esta sería un lugar de aprendizaje que sirve para no cometer en el presente y futuro los mismos errores del 
pasado. Es importante considerar que esto no es necesariamente así, pues que se conozcan los errores del pasado no garantiza que no se vuelvan a cometer, solo hace falta ver la historia contemporánea.

Relacionando esto al tema de libertad se puede decir que está en el yo, en el sujeto en plena libertad. Esto sigue siendo insuficiente pues la libertad no se desarrolla plenamente ya que el sujeto no interviene en la historia, debido a la dualidad sujeto-objeto existente, por tanto, no surge el movimiento del pensamiento que crea el absoluto y encamina a la libertad. El historiador ve a la historia como algo dado donde no puede intervenir ni trasformar, por tanto, la libertad tampoco puede desarrollarse.

Finalmente está la historia pensante, aquí el historiador toma el papel de filósofo y por ende realiza un proceso de síntesis dialéctica entre la inmediatez y la distancia, "mostrar cómo el espíritu se desarrolla en 190 el tiempo y se concreta en el espacio" (p. 42). Se produce un Aufhebung. Se toma conciencia de que hay una inmediatez en la cosa, pero al ser insuficiente es necesario un trabajo de distanciamiento, es decir hay una distancia reflexiva con el objeto. El Aufhebung da lugar a esta consideración pensante de la historia, donde se debe vincular historia y razón, pues la misma razón nace en la historia. Este vínculo nos permite pensar en el desarrollo de la libertad, pues no es un principio dado en el yo, sino que se realiza en la historia.

La libertad se entiende como síntesis, al entender el juego de distanciamiento e inmediatez y la participación mutua del sujeto y el objeto se puede entender la historia, pues se puede trasformar la historia y desarrollar la libertad en ella. En este sentido sujeto y objeto están contaminados, historiador e historia están contaminados uno en el otro y ahí se puede cultivar la libertad. Ya no hay una identificación ni un dualismo, sino un juego dialéctico donde aparece el absoluto y por tanto la posibilidad de libertad al trasformar la historia.

En este sentido, después de apreciar brevemente algunos puntos importantes de la filosofía de la historia dentro del pensamiento hegeliano se puede apreciar que el alemán, como ya se ha mencionado, en principio, no parece aludir a un final de la historia, de hecho, como plantea Anderson (1992) "resulta difícil encontrar en sus textos una frase semejante" pero enseguida hay que añadir que "la lógica del sistema de Hegel en su totalidad la exige prácticamente en cuanto conclusión, como tampoco cabe duda acerca de que hay suficiente evidencia para pensar que la asume en varios aportes de su obra" (p. 17).

Por tanto, se puede afirmar que Hegel nunca planteó el fin de la historia en esos términos, pero sí que inspiró estas lecturas o deducciones 
en autores como Kojève quien plantea propiamente el fin de l'histoire como un aporte original como se verá a continuación.

\section{El fin de la historia en la interpretación de Kojève}

La idea que más repite Kojève (2013) es su libro Introducción a la lectura de Hegel es que "La Fenomenología del espíritu de Hegel es la historia entendida como llegada a su final" en este sentido, este libro representa la terminación de la esencia humana en dos lados, en el primero se encuentra el "desenvolvimiento activo de esta esencia", y el segundo es, como expone Jiménez (2013) el "desenvolvimiento contemplativo de su propia auto comprensión” (p. 9).

Es interesante apreciar aquí que Kojève al intentar explicar el pensamiento hegeliano llega a algo nuevo, en este sentido su interpretación es fallida, sin embargo, aporta ideas completamente originales y lúcidas, como advierte Cadahia (2012) "a través de la máscara de Hegel expuso su propio pensamiento" (p. 164). Y sus aportes son sumamente importantes, por ejemplo, también los realizó en lo que respecta a la dialéctica del amo y del esclavo.

Para Jiménez (2013) en la Fenomenología del espíritu Kojève ve la autocomprensión de la historia en el momento en que se cierra, donde el hombre se entiende en cuanto que hombre, esto es como un ser histórico que se consuma y se acaba. Este hombre históricamente acabado es el ser humano libre y reconocido, una síntesis de lo universal y lo particular.

La Fenomenología del espíritu es para Kojève (2013) una descripción fenomenológica de la existencia humana, es decir que ésta es descrita tal y como aparece o se manifiesta a quien la vive. La parte que concierne al presente análisis se puede apreciar con claridad cuando Kojève presenta la subdivisión C del capítulo VI donde se trata el Estado posrevolucionario, esto es el Imperio napoleónico, donde se afirma con claridad que "estamos en el final de la historia" (p. 190).

Para Kojève (2013), Hegel piensa el imperio napoleónico como un realidad total o definitiva, se trata de hecho de un Estado universal y homogéneo que reúne a la humanidad entera y suprime en su seno las diferencias, por ello ve imposible que puedan existir guerras o revoluciones, porque "el Estado ya no se modificará, que permanecerá eternamente idéntico a sí mismo" (p. 191). Esto implicará además que el hombre tampoco cambiará y la naturaleza estará acabada desde siempre "por consiguiente, la ciencia que describe correcta y completamente el Mundo napoleónico continuará siendo totalmente válida para siempre” (p. 191). 
Napoleón no puede faltar en la reflexión de Hegel, este es el ciudadano del Estado universal y homogéneo, es decir el hombre pleno y satisfecho. El francés, en cuanto hombre dentro del marco de pensamiento hegeliano, está conforme con el Estado que ha creado, él es el ciudadano quien "ofrece su obra, sabe lo que hace y no hace más que lo que sabe; por tanto, hay una coincidencia absoluta entre el Querer y el Saber" (p. 193). De este modo, Napoleón se eleva por encima del Sein y está realmente presente en el Mundo. Realizando una analogía con el cristianismo Kojève (2013) dice que, si Napoleón es el Dios revelado, Hegel es quien lo revela.

De acuerdo con Cadahia (2012) Kojève toma una posición clara frente a la lectura, esto más que una interpretación literal es una relectura desde su contexto "a partir de los años treinta y cuarenta del pasado siglo" (p. 164). Posteriormente se verá más en detenimiento las implicaciones 192 de estos nuevos aportes en el mundo contemporáneo y en la conformación de la posthistoria. Antes de ello es necesario visibilizar cómo se utiliza esta visión a favor de la democracia liberal en los planteamientos que realiza Fukuyama (1992) partiendo, aunque no reduciéndose, a un hecho histórico trascendente, el fin de la guerra fría.

\section{El fin de la historia desde Fukuyama}

El fin de la historia de Fukuyama (1992) es probablemente una de las obras más influyentes en el ámbito de la política por todas las implicaciones que ha tenido y tiene. Este autor plantea una polémica tesis que supondría que el liberalismo y su correspondiente aplicación democrática, serían nada menos que la mejor forma de encarnar un sistema de gobierno y esto lo demuestra su capacidad, según el autor, para vencer ideologías rivales tales como el comunismo, como principal contrincante, además del fascismo y la monarquía hereditaria. El estadounidense va aún más allá y afirma que "la democracia liberal podía constituir el punto final de la evolución ideológica de la humanidad y la forma final de gobierno, y que como tal marcaría el final de la historia" (p. 11).

Para hablar del fin de la historia Fukuyama (1992) se apoya en Hegel, en repetidas veces acude a su autoridad, sin embargo, como ya se ha podido apreciar sería Kojève (2013) quien plantee esta idea, pues Hegel nunca habla del fin de la historia, sino más bien de una meta como plantea Anderson (1992):

Hegel casi nunca habla de Ende (final) o Schluii (conclusión), sino que se refiere a Ziel (meta), Zweck (finalidad) o Resultat (resultado). La ra- 
zón es muy sencilla: en alemán no existe una palabra que combine los dos sentidos de la palabra "fin» en inglés (o en español): por un lado el de final, por otro el de propósito. A Hegel le interesaba sobre todo la segunda de estas acepciones (p. 19).

El liberalismo como sistema de gobierno, para Fukuyama (1992), está libre de contradicciones internas y esto es lo que ha hecho, entre otras causas, que tenga un gran éxito, en contraste las demás ideologías políticas que se han caracterizado por tener graves defectos e irracionalidades, que se pueden constatar al ver su colapso en la práctica. Sin embargo, el autor es consciente que el liberalismo ha producido falencias en principios básicos como la justica que, desde su perspectiva, son productos de una aplicación incompleta de los principios de igualdad y libertad. Nótese que para Fukuyama (1992) no existe por tanto una incoherencia en la democracia liberal per se, sino en su aplicación.

Las controvertidas ideas antes planteadas por Fukuyama (1992) tuvieron una reacción inmediata, el mismo autor pudo constatarlas. Las críticas están orientadas en torno a que, en primer lugar, la historia no tiene una finalidad porque la historia en sí misma no es "direccional, orientada y coherente" (p. 13). El estadounidense manifiesta por su parte que esto se debe a que la sociedad actual es tremendamente pesimista, y esto se debe, en gran medida, a las dos desoladoras guerras mundiales que tuvieron lugar en la primera mitad del siglo XX.

Lo que se constató es que la ciencia fue utilizada para la guerra y la desolación, se presenció el alzamiento de regímenes totalitarios atroces, la destrucción del medio ambiente, en otras palabras, el hombre contra el hombre. Para Fukuyama (1992) esto, evidentemente, no era culpa del liberalismo, pero sí de que los seres humanos hayan desarrollado un supuesto pesimismo que no nos deja ver las cosas buenas que nos trae la historia, como la democracia liberal. No se puede evitar ver aquí rezagos de la visión de la historia como determinada y guiada por la providencia como planeaba Agustín.

Una de las premisas de liberalismo económico se encuentra en el mercado libre o más conocido como el libre mercado, que Fukuyama (1992) ve con optimismo al ser responsable de "producir niveles sin precedentes de prosperidad material" (p. 14). Sin embargo, frente a estas aseveraciones Cadahia (2012) se pregunta "si el Estado democrático liberal ha triunfado sobre las otras ideologías, ¿por qué persisten los conflictos?” (p. 173). Aquí es donde entra de lleno el constructo del fin de la historia y su correspondiente posthistoria, pues habría unos países que abrían llegado a la luz que supuestamente es la democracia liberal de mercado, y 
otros países que aún están en las tinieblas intentando alcanzar esta meta, "el mundo estaría dividido entre una parte que todavía sería histórica y una parte que ya sería posthistórica" (p. 173).

Se puede constatar claramente que Fukuyama (1992) pone el pensamiento de Hegel, y sin saberlo el de Kojève (2013), al servicio del liberalismo y con el del nuevo orden mundial, "hace del auge del capitalismo liberal el lugar donde vienen a resolverse todas las contradicciones de la historia" (Cadahia, 2012, p. 173). Muchos de los discursos actuales toman gran parte de los planteamientos realizados por Fukuyama, que permean en el imaginario social.

El discurso de Fukuyama (1992), a su pesar, no sigue los planteamientos hegelianos, pues en muchos aspectos son totalmente tergiversados, por ejemplo manifiesta Cadahia (2012), invierte "el rol atribuido 194 por Hegel a la sociedad civil y el Estado" (p. 173). Dentro del marco de pensamiento liberal prima la individualidad y no lo social, y esto precisamente no concuerda con el pensamiento hegeliano pues en él, el Estado tiene por objeto "regular la brecha entre la miseria y la riqueza" (p. 174).

El fin de la Guerra Fría pareció darle la razón a Fukuyama y permitió que la ficción de un triunfo irrefutable del liberalismo democrático se consolidará, sin embargo, actualmente el panorama ha cambiado, como manifiesta Cadahia (2012) y "la emergencia de nuevas superpotencias económicas, parecen poner en peligro el orden existente" (pp. 174-175). En este sentido se marca una vuelta a la historia como plantea Kagan (2008) quien sostiene que "la historia ha vuelto y las democracias deben unirse para darle forma, de lo contrario otros lo harán por ellas" (p. 3). Pues asumiendo una visión pensante de la filosofía de la historia, el ser humano puede y debe intervenir en la historia al no estar determinada, como la herencia agustiniana nos ha hecho creer.

\section{San Agustín y el fin de la historia}

Como ya se ha mencionado varias veces Fukuyama (1992) se apoya en la autoridad de Hegel para plantear el fin de la historia con su gran carga geopolítica. Sin embargo, esta tesis se vincula mucho más con Kojève (2013) y a juicio del autor, existe una relación inconfesada con San Agustín. La visión histórica del cristianismo plantea una teología basada en una finalidad, que para esta religión sería la salvación. Esto implica varias cosas, entre ellas una direccionalidad y linealidad de la historia. 
Hay que comenzar visibilizando que la obra La ciudad de Dios. Contra paganos de San Agustín no es un mero tratado teológico, de hecho, ya en su subtítulo se evidencia y demuestra que esta obra tiene un claro carácter político. Contextualizando esta obra hay que decir que fue escrita en respuesta la crisis del cristianismo debido a la invasión del Imperio Romano, como plantea Ramos (2008): "reflexión de San Agustín frente a los acontecimientos que le toca vivir" (p. 4). La aparentemente invencible Roma fue conquistada y saqueada, como recuerda Montes (1994) "la Ciudad Eterna tuvo que confesarse mortal" (p. 2).

San Agustín está tratando de disputarle a los paganos el sentido del imperio Romano. Dios le dio el poder a Roma para convertirse en imperio, Dios lo decidió así, la causa del poderío del imperio Romano viene dada por la religión cristiana. Por tanto, la tarea de su obra es justificar y desvanecer los cuestionamientos surgidos contra la religión cristiana fruto de la caída de Roma, "su pensamiento es doblemente escatológico" (p. 5).

Una de las implicaciones fundamentales de esta obra es la visión lineal de la historia que impronta, en contraste con la visión circular griega. Para San Agustín (1994) es la Divina Providencia, entendida como voluntad de Dios, quien guía y "establece los reinos humanos" (p. 2). El punto principal que interesa destacar de su obra es la distinción de dos tipos de ciudades: la ciudad de los hombres, la terrenal en contraposición de la ciudad de Dios, la celestial. En este sentido, se genera una duplicación de la noción de historia, hay una historia profana y por otro lado una historia sagrada, "Él es quien da la felicidad, propia del reino de los cielos, a sólo los hombres religiosos. En cambio, el reino de la tierra lo distribuye a los religiosos y a los impíos, según le place" (p. 34). La ciudad celestial se puede visibilizar en la ciudad mundana en ciertos momentos.

Por todo lo anterior será San Agustín (1994) quien sienta las bases para una idea de progreso en la historia terrenal. Y los planteamientos de Fukuyama (1992) parecen centrase en la herencia de esta tradición teológica teleológica antes que en los aportes de Hegel como él plantea en su obra. Este metarrelato se constituirá como mecanismo de dominación en el mundo contemporáneo.

\section{Dominación y fin de la historia}

El fin de la historia ha marcado la matriz de pensamiento contemporánea, esto incluye las matrices discursivas de dominación, es por ello necesario plantea Cadahia (2012) “pensar la experiencia biopolítica contemporánea 
en clave posthistórica" (p. 163). Para ello es fundamental considerar los discursos antes planteados sobre el fin de la historia de Kojève (2013) y Fukuyama (1992), quienes sentaron algunas de las bases para que esto se produjera.

Para Cadahia (2012), el fin de la historia de Kojève viene marcado por el estado postrevolucionario, el cual se caracteriza por ser homogéneo y universal donde el hombre propiamente dicho "desaparece, siendo progresivamente reemplazado por el animal de la especio Homo sapiens" (p. 165). Cadahia (2012) siguiendo a Bataille no está de acuerdo con esta afirmación y manifiesta que "si bien hemos ingresado a la posthistoria, aún sobrevive un resto sagrado, entendido como una negatividad sin empleo presente en las formas del arte, erotismo y la risa" (p. 168). La posición de Kojève le causará problemáticas y terminará por acercarse a la posición de Bataille como señala Cadahia (2012) "su viaje a Japón le ayudará a alejarse de esta creencia" (p. 169).

Agamben (2002) también reflexionará en torno al fin de la historia, concretamente sobre el hombre, a quien considera como "un campo de tensiones dialécticas ya cortado por cesuras que separan siempre en él -al menos virtualmente- la animalidad antropófora y la humanidad que se encarna en ella (p. 28)". Esto, plantea Cadahia (2012) desemboca en el problema de "el cuerpo del siervo como objeto del biopoder" (p. 175). Pues como consecuencia lógica del fin de la historia aparecerá la posthistoria y la humanidad ingresará a ella tomando el control de la gestión de esta animalidad que plantea Agamben, a través de tres figuras distintas, las cuales son "el genoma, la economía global y la gestión humanitaria" (p. 175).

Las figuras antes mencionadas permiten controlar o posibilitar la gestión de la animalidad, en este sentido la propuesta que realiza Agamben y rescata Cadahia (2012) es repensar la maquinaria antropológica que hace esto posible, "la relación de diferenciación y articulación entre lo humano y animal es el resultado de una maquinaria antropológica que atraviesa a toda la cultura occidental" (p. 176). Sin embargo, el intento de disolver la maquinaria antropológica no es exitoso pues como advierte Cadahia "solo consigue detener la maquinaria antropológica que critica a través de la configuración de otra maquinaria antropológica" (2012, p. 177). Es interesante apreciar el camino que realiza Agamben (2002) con la identificación de los mitos sobre los cuales se construyen la posibilidad de la gestión de la animalidad, especialmente aquel que permite diferenciar la animalidad de lo humano, que es lo que el autor termina por negar.

El fin de la historia, según Cadahia (2012), en principio parece tener dos posibles desenlaces para el ser humano, por un lado, elegir la 
forma de esclavo satisfecho y con ello alienarse bajo el capitalismo, o ser esclavos insatisfechos "eclipsado por el discurso del amo y su relato del fin de la historia" (p. 179). Cadahia (2012) al igual que Butler (2001), sobre el pensamiento foucaultiano, advierten que no es suficiente con la interpretación de Kojève de la posible liberación del hombre a través del trabajo pues ya no se trata de que exista una esclavización exterior, sino más bien una autoesclavización "Foucault ha señalado que el objeto de la política moderna no es ya liberar al sujeto, sino más bien indagar en los mecanismos reguladores a través de los cuales se produce y se mantiene a los sujetos" (p. 44). En este sentido lo que existe, como avizora Cadahia (2012) es "un movimiento de falsa liberación que no logra salir de los límites de una supuesta esencia o subjetividad trabajadora, autoimpuesta en cierta medida por el amo para quien el esclavo trasforma el objeto" (p. 180).

De lo anterior se desprende que existe cierto optimismo en la interpretación de Kojève (2013) al pensar que el hombre solo necesita del trabajo para liberarse, pues existen al menos dos momentos para que esto suceda, como recuerda Cadahia (2012), "una vinculado con la sujeción y otro vinculado con la subjetivación" (p. 180). La misma autora identifica la ironía de la historia en que estos dos momentos hayan coincidido en la conciencia servil, que también estudia Butler (2001) en su lectura sobre Hegel desde una perspectiva diferente.

\section{Sujeto formado en la sujeción}

Generalmente cuando se entiende el poder como forma de dominación se acostumbra a pensar, como recuerda Butler (2001) en el "poder como algo que ejerce presión sobre el sujeto desde fuera, algo que subordina, coloca por debajo y relega a un orden inferior" (p. 12). Gracias a los aportes foucaultianos (2003) se sabe que el poder o concretamente la dominación no es solo exterior al sujeto, sino que es algo que forma o constituye al mismo sujeto. Por ejemplo, en el capítulo tres denominado Disciplina se muestra como los "métodos que permiten el control minucioso de las operaciones del cuerpo, que garantizan la sujeción constante de sus fuerzas y les imponen una relación de docilidad-utilidad" (p. 141). Sin embargo, será Butler (2001) quien magistralmente complemente esta teoría con su interpretación de la conciencia desventurada de la Fenomenología del espíritu de Hegel. A partir de ella se esclarecerá como el sujeto se forma en la subordinación, es decir, el problema de la sujeción. 
Para contextualizar los aportes de Butler (2001) es imprescindible recordar brevemente la transición de las secciones Señorío y servidumbre y La libertad de la autoconciencia del libro ya mencionado de Hegel. En estos capítulos ya están visibilizadas las figuras del esclavo y del amo donde el primero aparece como "un cuerpo instrumental cuyo trabajo provee al amo de las condiciones materiales de su existencia y cuyos productos materiales reflejan tanto su subordinación" (p. 47) y la correspondiente dominación del amo. En las interpretaciones tradicionales es a través del trabajo que el esclavo conseguiría una supuesta liberación o autonomía de las que la autora se distancia.

La división entre amo y esclavo se da en un primer momento por la confrontación a vida o muerte por la cual el esclavo accede a convertirse en el cuerpo del amo debido al miedo absoluto a morir, pues "la 198 estrategia de dominación tenía como finalidad sustituir la lucha a vida o muerte" (p. 53). Al final de la sección el esclavo, dándose cuenta de su capacidad formativa, se convierte en amo de sí mismo, sin embargo, a un gran precio, el surgimiento de la denominada conciencia desventurada.

La conciencia desventurada sigue siendo una forma de servidumbre, ya no impuesta desde fuera por el amo, sino desde dentro del mismo sujeto traduciéndose en que "el sujeto se ve subordinado a las normas y estas son subjetivadoras, es decir, confieren forma ética a la reflexividad del sujeto emergente" (p. 54). En otras palabras, el amo ya no está fuera de nosotros, ahora está dentro de nosotros mismos.

Tanto Butler (2001) como Cadahia (2012), desde caminos diferentes, ven un posible camino de exploración mediante el cual sería posible superar esta conciencia servil, esta autoesclavización, pues "el sujeto ético-político foucaultiano, convertido en objeto/sujeto de los dispositivos de poder y resistencia, sigue estando firmemente situado en el terreno de la historia y en la posibilidad de su transformación" (p. 181) en este mismo sentido hablando de los mecanismos psíquicos de poder "la supresión no sólo conduce a su opuesto [...] sino que en formulaciones más contemporáneas lleva a definir al sujeto como una institución que desborda el marco dialéctico que lo genera" (p. 68).

Las reflexiones anteriores en este sentido no son pesimistas, pero sí evidencian toda una compleja trama de relaciones de poder a las que el mismo Foucault no dio una salida clara y convincente, pues como nos recuerda Zizek (2001), al reconocer la continuidad de la resistencia y el poder, acepta también tácitamente que "no basta como base de una resistencia efectiva, de una resistencia que no forme parte del juego sino que le permita al sujeto asumir una posición exterior al modo disciplinario/ 
confesional" (p. 267). Zizek acusa a Foucault de olvidar un concepto clave para pensar al sujeto, y este sería el de antagonismo el cual "de la producción de un excedente de resistencia, el propio antagonismo intrínseco de un sistema puede muy bien poner en marcha un proceso que lleve a su derrumbe final" (p. 273).

Cadahia y Butler, desde perspectivas diferentes, plantean que una filosofía pensante de la historia unida con la consideración de que existe una relación dialéctica entre poder y libertad nos permiten ser conscientes de que es posible trasformar la historia y resistirse a las estrategias de dominación e incluso subvertirlas. Ahora bien, desde el campo educativo, ¿cuál es la relación entre ella y la sujeción?

\section{Educación y sujeción}

La educación en cuanto saber constituye determinadas instituciones que a su vez legitiman un tipo de entramado discursivo del que emerge un tipo de sujeto, en este caso, el estudiante que hay que educar. Como es de conocimiento general, la microfísica del poder muestra cómo se producen sujetos normalizados y dóciles a través de diversas instituciones.

De acuerdo con Ball (1990) Foucault "nunca dedicó a la educación un trabajo sistemático y acabado, pero se refiere a pedagogías, sistemas educativos, dispositivos de examen" (p. 14). Una de las tesis fundamentales que se pueden deducir a través de sus aportes es que "las escuelas, como las cárceles y asilos, se preocupan fundamentalmente por la regulación moral y social" (p. 18). La educación formal se constituye como una enorme maquinaria que es capaz de objetivar a los sujetos a través de distintos procesos de clasificación y división, utilizando diversas técnicas, entre las que destaca el examen. De este modo se van construyendo identidades y subjetividades que son "centrales en los procesos organizativos de la educación en nuestra sociedad" (p. 8). Además, es importante mencionar que el profesor es quien tiene toda la autoridad y es capaz de dominar al estudiante desde diversas prácticas tales como el castigo, el premio o los refuerzos. Todas estas praxis moldean a los estudiantes a un tipo de sujeto sumiso necesario que, en el siglo XVI, era un obrero para la fábrica.

La escuela, al igual que la prisión, se constituye sobre la base de diferentes discursos que constituyen aquello que puede ser dicho y pensado creando relaciones de poder y subjetividades. Uno de los elementos fundamentales son los saberes de las denominadas Ciencias de la educación "prácticas divisoras están críticamente interconectadas con la formación 
y la elaboración cada vez más compleja de las ciencias de la educación: psicología de la educación, pedagogía, sociología de la educación, psicología cognitiva y evolutiva" (p. 8). En la actualidad todas estas disciplinas se han consolidado y a la par han intentado sostener su estatuto epistemológico, incluso se han nutrido de un conjunto de saberes emergentes de diversos ámbitos. Desde la autoridad de estas disciplinas se naturaliza la escuela en cuanto institución reproductora de desigualdades.

Además de los exámenes, premios, castigos, refuerzos y saberes que legitiman la educación se puede indagar acerca de personajes tan importantes como el maestro y su rol en la educación. Se le da una categoría de biomaestro que se tuvo que alejar de "una disciplina bruta y mecánica" (p. 76) por las críticas recibidas. No obstante, se buscaron nuevas estrategias que se fundamentaban en "las nuevas verdades de la medicina y la psico200 logía” (p. 77). De este modo el profesor se va convirtiendo poco a poco en una especie de profesional similar al médico en cuanto agente de normalización, pues es capaz de casi "diagnosticar" y "curar" a los estudiantes.

La escuela tendría su origen como maquinaria a partir del siglo XVI, donde se asientan las bases de la institución que se conoce en la actualidad. Es sumamente importante señalar los aspectos que se han consolidado para la existencia de la educación formal de niños y adolescentes que plantean Varela y Álvarez (1991): la definición de un estatuto de la infancia; la emergencia de un espacio específico destinado a la educación de los niños; la aparición de un cuerpo de especialistas de la infancia dotados de tecnologías específicas y de «elaborados» códigos teóricos; la destrucción de otros modos de educación y finalmente la institucionalización propiamente dicha de la escuela: la imposición de la obligatoriedad escolar decretada por los poderes públicos y sancionados por las leyes.

Se puede apreciar claramente que todos los elementos anteriores se han tenido que conformar para que la idea de escuela aparezca y con ella su naturalización, "búsqueda arqueológica con el fin de poner al descubierto los cimientos sociopolíticos sobre los que se asienta la génesis de la escuela primaria obligatoria" (p. 175). El éxito de lo anterior se puede ver en la actualidad pues en el imaginario social se tiene una noción de niño y adolescente kantiana (2004) que tiene que buscar la "salida de la minoría de edad" (p. 92) con todo lo que ello implica.

La escuela, tal y como se la conoce, surgió como un espacio de civilización para el niño obrero. Además, se cuestiona fuertemente el proceso de normalización que sufre la escuela que a juicio de Varela y Álvarez (1991) “es vista cada vez más como un proceso natural" (p. 175). Se puede 
decir que la escuela está constituida como un elemento fundamental de todas las sociedades y pese a las numerosas críticas aparece un elemento necesario para la aseguración del futuro. Es importante analizar uno de los saberes que lo legitima, la pedagogía, nacida a partir de los aportes de Kant, dentro de una corriente que se puede llamar idealismo alemán.

\section{El surgimiento de la pedagogía}

Es necesario situarse a fines del siglo XVIII y siglo XIX, concretamente en la tradición de la filosofía alemana que juega un papel fundamental en la conformación de aquello que se denomina pedagogía en la actualidad. A partir de sus raíces, aparecen dos visiones diferentes, como recuerda Vázquez (2012) por un lado, está la heredada de Herbart con su visión científico-mecanicista y por otro la cultivada por la filosofía historicista por Dilthey. De estas dos filosofías se pueden distinguir dos caminos para la pedagogía "de la pedagogía normativa representada por autores neokantianos, como Natorp y otros de inspiración cristiana, como Henz y F. März-y la de la pedagogía empírica” (p. 8).

Para la pedagogía normativa esta disciplina es indudablemente una ciencia pues estaría soportada o estrechamente vinculada con la ética y con la psicología, ambas preocupadas por lo que Kant llamaría razón práctica entendida esta "como autónoma al modo, kantiano, ya sea iluminada por la revelación cristiana" (p. 8). Se puede visibilizar desde este punto, la histórica visión de la educación como un actuar bien, o mejor un deber ser, donde la ética juega un papel fundamental. La psicología por su parte se encarga de legitimar de alguna manera los comportamientos en los estudiantes.

Por otro lado, la línea historicista tomará cuerpo con los aportes educativos de Scheleimarcher para quien la ética no es universal, sino que responde a "condiciones histórico-sociales" (p. 8). Aquí los planteamientos se orientan a una formación de los jóvenes por parte de los adultos mayores al ser la educación un proceso histórico de formación de las generaciones sucesivas.

Se puede apreciar en los dos casos anteriores un factor común a ambas líneas donde la razón al estilo kantiano es la que juega un papel fundamental pues "filosofía y pedagogía se halla en la concepción de la razón y de su alcance, tal como la planteaba Kant” (p. 9). No es de extrañar que hasta la actualidad la búsqueda del conocimiento sobre una base puramente racional siga aún vigente. Numerosos autores han criticado 
que en las mallas curriculares por ejemplo sea extraño encontrar disciplinas como el arte, la música o la educación física. Si es que aparecen es con una importancia muy inferior a otras, donde la creatividad, tradicionalmente, no ha ocupado un papel importante.

La nominación de pedagogía corresponde a la ya clásica división entre Ciencias de la naturaleza y Ciencias del espíritu. Para Dilthey evidentemente la pedagogía estará en este último grupo porque "la educación no es propiamente un quehacer técnico, ni tampoco un dejar crecer sino un introducir al educando en el mundo de sentido, de valores, del deber ser" (p. 10). Además, se suma al enfoque hermenéutico planteando que lo propio de la educación es el comprender y no el explicar que sería propio de las Ciencias de la naturaleza. Esta tendencia dominaría la pedagogía hasta los años sesenta y setenta coincidiendo con la crítica de la filosofía alemana y su razón instrumental. Es importante mencionar que la denominación de Ciencias de la Educación tiene una genealogía distinta, que por sí sola merece un análisis más detallado vinculado a una visión cientificista, como plantea Higuera (2013), que se traduce en que: "Un alto número de personas de Occidente reconoce como única verdad aquella científica basada en hechos" (p. 24).

La Escuela de Frankfurt, siguiendo a Vázquez (2012), sería la que incluirá una dimensión aparte a la pedagogía, de este modo "proponen un concepto de educación, como obra de emancipación y para la pedagogía [...] la hermenéutica crítica centrada en la reflexión acerca de las condiciones sociales en que se desarrolla la educación" (p. 10). De este modo el proceso educativo no se da en un espacio descontextualizado, sino que responde a un tiempo y un espacio. Aún en la actualidad sigue muy vigente la idea central de emancipación como objeto fundamental de la educación. En cierto modo el educar para un deber se puede orientar a cierto tipo de adoctrinamiento y es precisamente el riesgo que estos pensadores fueron capaces de advertir.

En Latinoamérica también surgieron cuestionamientos a un tipo de educación que el brasileño Paulo Freire (1984) denominó como bancaria. En su lugar él propone una pedagogía del oprimido que busca una liberación y que tiene como categoría fundamental la esperanza:

Mientras que en la práctica domesticadora el educador es siempre el educador del alumno, en la práctica liberadora, en cambio, el educador debe "morir" en cuanto educador exclusivo del alumno, a fin de "renacer" en cuanto alumno de su alumno. Simultáneamente debe proponer al alumno que "muera" en cuanto alumno exclusivo del educador, a fin de "renacer" en cuanto educador de su educador" (p. 77). 
La crítica fundamental realizada a la pedagogía de los teóricos de las Ciencias del Espíritu, recoge Vázquez (2012), es que pertenecen “a una ideología que enmascara bajo abstracciones — libertad, desarrollo personal- el fracaso escolar y la discriminación" (p. 12). En este sentido, no se ve ya la educación como un lugar donde el lumen ratio debe ser capaz de iluminar las prácticas sociales, sino que se trata de una crítica frontal a esas praxis en sus manifestaciones incoherentes y contradictorias.

\section{Educación: ¿Esperanza o sujeción?}

Paulo Freire (1993) es uno de los principales pensadores en lo que al movimiento de educación liberadora se refiere desde una visión crítica a la escuela. Su obra Pedagogía de la esperanza se piensa a sí misma como un reencuentro con su obra más célebre, Pedagogía del oprimido y, precisamente en ella, responde a las numerosas críticas que el autor recibió en esta obra "acusando al sueño y la utopía no solo de ser inútiles, sino también de ser inoportunos” (p. 23).

Es importante considerar que Freire no era un apologeta acrítico de la escuela, pues al igual que muchos otros pensadores criticó duramente el rol real de la educación en la sociedad. Concretamente se puede decir que realizó un fuerte cuestionamiento a la educación tradicional de su tiempo, y con ello también a la relación estudiante-maestro. Freire, pese al duro cuestionamiento realizado, se aleja radicalmente de los planteamientos realizados por Foucault donde predomina claramente una visión algo pesimista del mundo, y donde la escuela no tendría, en principio, salvación posible. Según Zizek (2001) el error del autor francés es, por paradójico que parezca, el sujeto, pues para el esloveno es claro que el sujeto por definición propia es un "excedente sobre su causa" (p. 273). De este modo no existe salida posible pese a la resistencia que plantea Michel Foucault (2003), y siguiendo estos postulados tampoco la habría para la escuela en cuanto ente reproductor del poder y por tanto de los entramados de poder e inequidades sociales.

Las mallas de poder que parecen rodear a la escuela y sus estrategias de dominación parecen mostrar un callejón sin salida del que no es posible salir. Freire (1993) por el contrario plantea una categoría ontológica que es necesario mantener en contextos tan desalentadores: "La esperanza es una necesidad ontológica: la desesperanza es esperanza que, perdiendo su dirección, se convierte en distorsión de la necesidad ontológica" (p. 24). 
La educación en sí misma puede ser totalmente desechada o aun peor, ser vista como una maquinaria que no es posible cambiar y por tanto entra en un sentimiento de desesperanza que lejos de permitirnos cambiar la realidad "nos hace sucumbir al fatalismo en que no es posible reunir fuerzas indispensables para el embate recreador del mundo" (p. 24). Esta tesis Freiriana es fundamental para el análisis de la escuela como posible elemento de resistencia y liberación. Existen por tanto dos posibilidades de actuación ironiza Gonfiantini (2007): "sentarnos a llorar sintiéndonos presos de las estructuras de poder o plantearnos una ubicación distinta considerando que las instituciones son también lugares de mediación, oposición y nuevas posibilidades" (p. 94)

A lo largo de todo el texto se responden o aclaran muchos de los temas nodales planteados en su obra por excelencia, Pedagogía del oprimido, tales como la acusación de una especie de teleología de la historia donde la liberación se plantearía como una especie de fin. Al respecto Freire (1984) plantea que no es ni mucho menos una finalidad, sino una utopía creadora que es necesario visualizar para construir.

La educación que se propone no responde al enseñar una gran cantidad de contenidos a los estudiantes sino de concientizar en ellos que esos contenidos aparentemente neutros y objetivos. Es exactamente en este punto donde reside la importancia fundamental de la educación como acto de conocimiento no sólo de contenidos sino de la razón de ser de los hechos económicos, sociales, políticos, ideológicos, históricos que explican el mayor o menor grado de interdicción del cuerpo consciente a que estemos sometidos (p.129).

La propuesta freirana busca por tanto destacar el aprendizaje y la enseñanza sobre el pilar de lo que él llama comprensión crítica. En este sentido, se cuestiona el modelo tradicional de trasmisión pasiva de conocimientos de docentes a estudiantes y su correspondiente alienación. La concientización viene como concepto semejante a lo que debería ser la escuela, pues sin ella no hay cambio posible. Respecto a su concepción acerca del sujeto se puede decir que coincide con Aguilar (2009) en que "Desde el ámbito latinoamericano, ser sujeto deberá entenderse como el acto autoafirmativo mediante el cual el sujeto se posiciona y apropia de su contexto para valorarlo y ejecutar sus acciones protagónicas" (p. 67).

Muchos de los planteamientos de Freire tienen una inspiración claramente marxista, pues cuando habla de opresores y oprimidos, en principio, se puede ver una clara analogía entre burgueses y proletarios. La crítica realizada al capitalismo es retomada por Freire en el campo 
propiamente educativo, es necesario recordar que para Marx (2011) debía haber un empoderamiento de esta clase social oprimida, "el proletariado, capa inferior de la sociedad actual, no puede levantarse, no puede enderezarse, sin hacer saltar toda la superestructura formada por las capas de la sociedad oficial" (p. 126). Salvando las diferencias la propuesta de Freire tiene puntos en común, pues también se visibiliza cierta dicotomía que se podría catalogar de dialéctica.

Paulo Freire es un referente en lo que a educación se refiere, además su contexto latinoamericano lo hace especialmente interesante para la realidad ecuatoriana. En su famosa obra Pedagogía del oprimido planteó una educación para las personas que han estado invisibilizadas a lo largo de la historia. En este sentido él se orientó a un tipo de educación que permitía a las personas liberarse de las cadenas que les atan a través de una praxis política. Cuestionó la concepción de alfabetización de su tiempo como el mero hecho de aprender a leer y escribir en sentido reducido, por el contrario, avizoró una alfabetización en la que la persona pudiera llegar a ser un ente activo de la sociedad y participar políticamente, para poder ejercer y defender sus derechos, en este sentido, siguiendo a Moreno, (1980) "el objetivo primordial de la educación es esa concientización con sentido crítico, que comprometa a la acción" (p. 523).

\section{Conclusión}

A lo largo del presente trabajo, en la primera parte se han presentado de forma breve las principales líneas de la filosofía de la historia presente en Hegel, a juicio del autor, marcadas por el desarrollo de la libertad y el papel de la historia e historiador y su relación sujeto-objeto. Se ha podido apreciar que el fin de la historia como tal no es un constructo teórico realizado por Hegel, sino por sus comentaristas y lectores, este es el caso de Kojève (2013). Es importante mencionar que muchos de los lectores mencionan que pese a que Hegel no planteara el final de la historia sus planteamientos hacen que sea deducible.

Por otro lado, Kojève (2013) llevó a cabo un intento de interpretación de los textos Hegel donde se pudieron visibilizar sus planteamientos originales, entre los que destaca el fin de la historia, que viene dado por la construcción de Estado homogéneo y universal. Esta lectura sembraría un precedente que retomaría Fukuyama (1992) en una lectura liberal donde su aplicación democrática sería el fin de la historia en cuanto meta, hacia donde todas las naciones deben llegar entrando en lo que se llamará 
poshistoria. Sobre estos sucesos se consolidará una maquinaria antropológica de dominación.

Los argumentos que realiza Fukuyama (1992) están basados en concepciones históricas que no son hegelianas, sino que más bien dejan ver matices deterministas donde existe una Providencia que guía la historia hacia lo mejor, en este caso la democracia liberal. Sin embargo, se puede ver que este orden mundial está en crisis por sus falencias internas, donde no existe justicia ni equidad, sino competencia y acumulación.

Con la ayuda de Cadahia (2012) y Butler (2001) se ha evidenciado como el fin de la historia y su correspondiente posthistoria crearon una serie de mecanismos de dominación que ya no se encuentran fuera de los sujetos, sino que están dentro de ellos bajo una forma de conciencia servil que genera autoesclavización a través de diferentes mecanismos.

Existe un camino por explorar, bajo la concepción de una historia pensante, en la que el ser humano puede actuar sobre la historia y por tanto transformarla, pues las estrategias de dominación se ven sobrepasadas por ellas mismas, hay una relación dialéctica entre poder y libertad que deja lugar a la praxis y a la esperanza por reencausar la historia.

En la segunda parte se ha intentado realizar un diálogo entre dos autores radicalmente distintos, Foucault (2003) y Freire (1993). A juicio del autor es importante usar la metodología genealógica para analizar el inicio de la escuela tal, además de visibilizar su rol perverso que no es posible ignorar para no caer en la ingenuidad de pensar una escuela neutra, objetiva y trasformadora cuando históricamente ha sido todo lo contrario. Sin embargo, es fundamental no quedarse únicamente en el pesimismo de Foucault, y es aquí donde Freire aporta una luz de posible futuro para la escuela, la esperanza.

Si la educación formal pretende mantenerse es necesario realizar una serie de cambios estructurales en numerosos aspectos: la relación docente-estudiante, la legitimación de los saberes, la horizontalidad, el no adoctrinamiento, la concientización, la praxis política y sobre todo la trasformación en forma de liberación social e individual. Estos cambios implican necesariamente la participación de distintos sectores sociales, en este sentido como mínimo deberían incluirse el Estado y la sociedad civil. Si ambos actores no colaboran el cambio no se podrá realizar desde un solo frente.

En conclusión, el autor tiene la convicción de que la escuela puede salvarse e ir más allá de lo que es, pero para lograrlo debe transformarse estructuralmente desde sus cimientos, y esta mutación debe darse desde numerosos lugares en los que ella está inserta, siendo parte de un sistema 
injusto mucho más amplio y complejo que es necesario trasformar teniendo siempre como referencia y una categoría ontológica fundamental, la esperanza.

\section{Bibliografía}

AGAMBEN, Giorgio

2002 Lo abierto. El hombre y el animal. Argentina: Ed. Adriana Hidalgo.

AGUILAR, Floralba

2009 Re-conceptualización de la subjetividad desde América Latina. Revista Sophia: Colección de filosofía de la educación, 7. Quito: Editorial Universitaria Abya-Yala.

\section{AGUSTÍN SAN}

1994 La ciudad de Dios. Barcelona: Porrúa

ANDERSON, Perry

1992 Los fines de la historia. Barcelona: Anagrama.

BALL, Stephen

1990 Foucault y la educación: disciplinas y saber. Madrid: Morata.

BUTLER, Judith

2001 Mecanismos psíquicos del poder. Teorías sobre la sujeción. Madrid: Cátedra.

CADAHIA, Luciana

2012 Nuestro amo juega al esclavo: la máquina antropológica moderna y la invención de la post-historia. En: M. Cereceda, \& T. Menegazzi, Animalismo y humanismo (pp. 163-181). Madrid: Arena.

DI CAUDO, María Verónica

2007 La construcción de los sujetos de la educación. Revista Sophia: Colección de filosofía de la educación, 2. Quito: Editorial Universitaria Abya-Yala.

FOUCAULT, Michel

2003 Vigilar y castigar. El nacimiento de la prisión. México: Siglo XXI.

FREIRE, Paulo

1993 Pedagogía de la esperanza. Madrid: Siglo XXI.

1984 Pedagogía del oprimido. Madrid: Siglo XXI

FUKUYAMA, Francis

1992 El fin de la historia y el último hombre. Colombia: Planeta.

JIMÉNEZ, Manuel

2013 Prólogo. En: A. Kòjeve, Introducción a la lectura de Hegel (pp. 9-39). Madrid: Trotta.

HIGUERA, Édison

2013 Pre-requisitos epistemológicos de la Filosofía de la educación. Revista Sophia: Colección de filosofía de la educación, 14. Quito: Editorial Universitaria Abya-Yala.

KAGAN, Robert

2008 The reutrn of history and the End of Dreams. New York.

KANT, Inmanuel

2004 ¿Qué es la ilustración? Madrid: Alianza. 
KOJÈVE, Alexandre

2013 Introducción a la lectura de Hegel. Madrid: Trotta.

MARX, Karl

2011 El manifiesto comunista. Madrid: Alianza Editorial

MONTES, F.

1994 Introducción a La ciudad de Dios. En: S. Agustín, La ciudad de Dios (pp.220).

RAMOS, Alejandro

2008 La ciudad de Dios en Santo Tomás de Aquino. Mar de la Plata: Universidad FASTA.

REALE, Giovanni, \& ANTISERI, Darío

1988 Historia del pensamiento filosófico y científico III. Del Romanticismo hasta hoy. Barcelona: Herder.

RUS, Salvador

2005 Estudio preliminar. En: F. Hegel, Lecciones sobre la filosofía de la historia universal (pp. 17-74). Madrid: Tecnos.

VARELA, Julia, \& ÁLVAREZ, Fernando

1991 La arqueología de la escuela. Madrid: La Piqueta.

VÁZQUEZ, Maris

2012 La filosofía de la educación. Buenos Aires: CIAFIC.

ZIZEK, Slavov

2001 El espinoso sujeto. Barcelona: Paidós.

Fecha de recepción de documento: 13 de diciembre de 2017

Fecha de revisión del documento: 15 de febrero de 2018

Fecha de aprobación del documento: 15 de mayo de 2018

Fechas de publicación del documento: 15 de julio de 2018 